\title{
Spatiotemporal changes of land desertification sensitivity in northwest China from 2000 to 2017
}

\author{
WEI Wei ${ }^{1}$, "GUO Zecheng ${ }^{2}$, SHI Peiji ${ }^{1}$, ZHOU Liang ${ }^{3,4}$, WANG Xufeng ${ }^{5}$, \\ LI Zhenya ${ }^{1}$, PANG Sufei ${ }^{1}$, XIE Binbin $^{6}$ \\ 1. College of Geography and Environmental Science, Northwest Normal University, Lanzhou 730070, China; \\ 2. College of Earth and Environmental Sciences, Lanzhou University, Lanzhou 730000, China; \\ 3. Faculty of Geomatics, Lanzhou Jiaotong University, Lanzhou 730070, China; \\ 4. State Key Laboratory of Resources and Environmental Information System, Institute of Geographic Sciences \\ and Natural Resources Research, CAS, Beijing 100101, China; \\ 5. Key Laboratory of Ecohydrology of Inland River Basin/Gansu Qilian Mountains Ecological Research Center, \\ Northwest Institute of Eco-environment and Resources, CAS, Lanzhou 730000, China; \\ 6. School of Urban Economics and Tourism Culture, Lanzhou City University, Lanzhou 730070, China
}

\begin{abstract}
Sensitivity assessment is useful for monitoring land desertification. Research into how to prevent and control desertification is also important. In the arid region of northwest China, desertification is becoming worse and is a serious problem that affects local sustainable development. Based on remote-sensing and geographic information system technology, this study establishes a "soil-terrain-hydrology-climate-vegetation" desertification sensitivity comprehensive evaluation system to reflect the spatiotemporal changes of land desertification, and proposes a spatial distance model to calculate a desertification sensitivity index. The spatiotemporal change characteristics of land desertification sensitivity in northwest China are quantitatively assessed from 2000 to 2017. Moreover, the main driving factors are analyzed using the geographical detector method. The results show the following. (1) Terrain, soil, climate, vegetation and hydrology affect and restrict each other, and constitute the background conditions of the distributions and changes of sensitivity to desertification in northwest China. (2) Desertification sensitivity generally displays a low distribution characteristic on the periphery of the area and a high one in the interior. The low-sensitivity regions are mainly in the five major mountain ranges (Altai Mountains, Tianshan Mountains, Kunlun Mountains, Altun Mountains and Qilian Mountains), while the high-sensitivity regions are mainly in regions such as the Junggar Basin, the Tarim Basin and the Inner Mongolia Plateau, as well as the Taklimakan Desert, Badain Jaran Desert and Tengger Desert. The spatial distribution of desertification sensitivity is obviously regional, and the high- and low-sensitivity regions have clear boundaries and a concentrated distribution. (3) With regard to spatiotemporal evolution, changes in desertification sensitivity since 2000 have been predominantly stable, and the overall sensitivity has displayed a slowly decreasing trend, indicating that potential desertification regions are decreasing annually and that some achievements have been made in the
\end{abstract}

Received: 2020-08-12 Accepted: 2020-10-20

Foundation: National Natural Science Foundation of China, No.41861040, No.41761047, No.41961027

Author: Wei Wei, PhD and Associate Professor, specialized in environmental RS and GIS application.

E-mail: weiweigis2006@126.com

"Corresponding author: Guo Zecheng, PhD Candidate, specialized in GIS application. E-mail: 18709424424@163.com 
control of regional desertification. (4) Soil and climate play a direct role in the driving factors of desertification in northwest China, and these have been found to be the most important influential factors. Vegetation is the most active and basic factor in changing the sensitivity. In addition, topography and hydrology play a role in restricting desertification changes. Socio-economic factors are the most rapid factors affecting regional desertification sensitivity, and their impacts tend to be gradually increasing. In general, desertification has been effectively controlled in northwest China, and positive results have been achieved in such control. However, against the backdrop of intensified global climate change, increasingly prominent human activities and new normals of socio-economic development, the monitoring, assessment and control of desertification in China still have a long way to go.

Keywords: desertification sensitivity; spatiotemporal change; geographical detector; GIS; northwest China

\section{Introduction}

Desertification is a natural phenomenon of land degradation in arid and semi-arid regions, and can be affected by climate change, human activities and ecological deterioration (Zhu, 1991; Li et al., 2018). As one of the global ecological-social-economic problems faced by the international community, it is attracting extensive attention all over the world (United Nations, 1994; Cui et al., 2011; Ahmed et al., 2020). Desertification leads to the occurrence of loose soil structure, nutrient loss, and vegetation coverage and biomass decline. It also leads to massive reduction of available land resources, which seriously reduces the production and living space of human beings and restricts the coordinated and sustainable development of the local ecological environment and social economy (Zhu, 1991; Sterk et al., 2016; Symeonakis et al., 2016).

Desertification is one of the most frequent and widespread natural events occurring in China. According to the statistical reports of the fifth bulletin on desertification, the total area of land desertification in China is about $172.12 \times 10^{4} \mathrm{~km}^{2}$, which accounts for one-fifth of the total land area (Cristina et al., 2017; Tian et al., 2018). Desertification is associated with climatic, hydrological and meteorological conditions that lead to vegetation decrease, land degradation and ecological deterioration, which have a negative effect on the living environment and sustainable development. The monitoring of desertification, as well as spatiotemporal changes and ecological sensitivity, is significant for ecological management and human settlement improvement. As a country seriously affected by desertification, research on desertification prevention and control in China is of utmost importance (Duan et al., 2018; Wang et al., 2018; Zhou et al., 2020). Therefore, desertification monitoring and evaluation, as well as the sensitivity of land desertification, have become important research fields for geographers, ecologists and many other scholars in related fields.

Desertification sensitivity refers to the change possibility of desertification under the influence of various factors and constraints (Symeonakis et al., 2016). The process of desertification is often closely related to topography, soil, vegetation, climate and human activities (Sterk et al., 2016; Cristina et al., 2017; Zhou et al., 2020). The sensitivity of land desertification can be used as an important index to monitor and forecast the degree of desertification in arid regions, to classify the sensitive areas of land desertification, to estimate the spatiotemporal evolution pattern and changing trend, and to provide a scientific basis for government planning and taking measures on desertification prevention and control (Karamesouti et al., 2018; Zhou et al., 2019). The evaluation of desertification sensitivity started 
started with the Mediterranean Desertification and Land Use (MEDALUS) project, which was proposed and funded by the European Union in 1991. The environmental sensitivity area (ESA) method can be used to evaluate land deterioration and desertification sensitivity through selection of soil, climate, vegetation, land management and other factors according to the framework of the MEDALUS project (Salvati et al., 2015; Tian et al., 2018). The ESA method is widely used to evaluate land deterioration and desertification sensitivity in different regions globally because of its simple, flexible, efficient and fast calculation (Symeonakis et al., 2016; Karamesouti et al., 2018). In China, some relevant studies have investigated sensitive areas of land desertification in arid regions based on the ESA method (Zhao et al., 2012; Cristina et al., 2017). However, the spatial distribution of desertification and its spatiotemporal changes are significantly different in the various regions of China's vast territory. The indicators and methods of ESA have been explored and developed based on the Mediterranean region, which does not fully reflect the situation of desertification sensitivity and changes in arid and semi-arid regions in China. Therefore, this method cannot be used directly to identify the sensitive areas of land desertification in China. Moreover, there are no unified standards and norms for selection of indicators, construction of the evaluation system and use of evaluation methods, which are subjective and monotonous to a certain extent. There is also a lack of comparison of dynamic changes in desertification sensitivity and a lack of discussion of the change processes involved. It is therefore difficult to systematically, scientifically and comprehensively provide scientific guidance and decisions for regional desertification control and ecological management. Thus, it is necessary to establish a simple and objective evaluation model for desertification sensitivity. Development of an accurate and realistic simulation and evaluation method for regional desertification sensitivity on a large scale and a spatiotemporal scale has become the research focus of many scholars.

The arid region of northwest China is one of the most serious desertification areas in China because of its unique geographical location far away from the ocean and deep in the hinterland of the continent, with scarce precipitation and strong evaporation. In recent years, remarkable progress has been made in desertification control and research in China, and many achievements have been made in desertification monitoring and evaluation (Wang et al., 2014; Cristina et al., 2015; Salvati et al., 2015). However, most research on desertification monitoring and evaluation in different subjects views it only as a single natural result and conducts experiments and observations in a laboratory on the microscale. Interpretation and extraction are from different remote-sensing images on the mesoscale, and monitoring and evaluation are on the macroscale. In fact, land desertification is the result of a series of interactions and influences of comprehensive factors, led by those of the regional environment (Liu et al., 2007; Xu et al., 2011; Zhou et al., 2019). Therefore, it is necessary to monitor and evaluate the spatial characteristics and evolution pattern of existing desertification and potential desertification from the perspective of the overall situation and microsystem.

This paper selects the arid region of northwest China as a typical study area to evaluate the sensitivity of desertification based on the basic principle of the ESA framework. Spatial analysis technology and the spatial distance model (SDM) were integrated to monitor spatiotemporal changes in land desertification sensitivity from 2000 to 2017 by establishing a comprehensive evaluation index system from aspects of the "soil-terrain-hydrology-climate 
-vegetation" system. Moreover, the main influential factors are discussed from theoretical and practical perspectives through the geographical detector and correlation analysis methods. The aim is to provide scientific support for control and prevention of desertification in the arid region of northwest China, and also provide some reference points for the identification and exploration of sensitive areas of desertification in other similar areas.

\section{Methodology}

\subsection{Study area}

The arid region of northwest China is located in China's western interior $\left(73^{\circ} \mathrm{E}-107^{\circ} \mathrm{E}\right.$, $35^{\circ} \mathrm{N}-50^{\circ} \mathrm{N}$ ). It includes Xinjiang Uygur Autonomous Region, five cities along the Hexi Corridor of Gansu Province and the Alxa region of Inner Mongolia (Figure 1), with a total area of $2.09 \times 10^{6} \mathrm{~km}^{2}$. The region has complex and diverse landscapes, with varied and rolling terrain, where the topography is mostly plateaus, mountainous regions and basins, comprising the Inner Mongolia Plateau, Altai Mountains, Altun Mountains, Tianshan Mountains, Kunlun Mountains, Qilian Mountains, Tarim Basin, Junggar Basin and Turpan Basin. The natural landscape constitutes a special geographical unit characterized by the coexistence of mountain-desert-oasis ecological systems. Due to the perennial influence of the continental climate, precipitation in the northwest arid region is rare, with an average annual precipitation of about $130 \mathrm{~mm}$, and a decreasing trend from east to west. Evaporation is strong (the average annual evaporation is between 800 and $3200 \mathrm{~mm}$ ), vegetation is sparse and the surface water is not sufficient to maintain normal growth of vegetation, which mainly relies on groundwater. Influenced by the climate, ecohydrology, landscape and other natural conditions, the soil and vegetation types of the region form an obvious vertical spectrum of soil-vegetation. Due to its arid climate, limited water resources and inappropriate water-related human activities, the region has suffered serious loss of natural vegetation, and gradual soil salinization and desertification, which have greatly impeded the sustainable development in future.

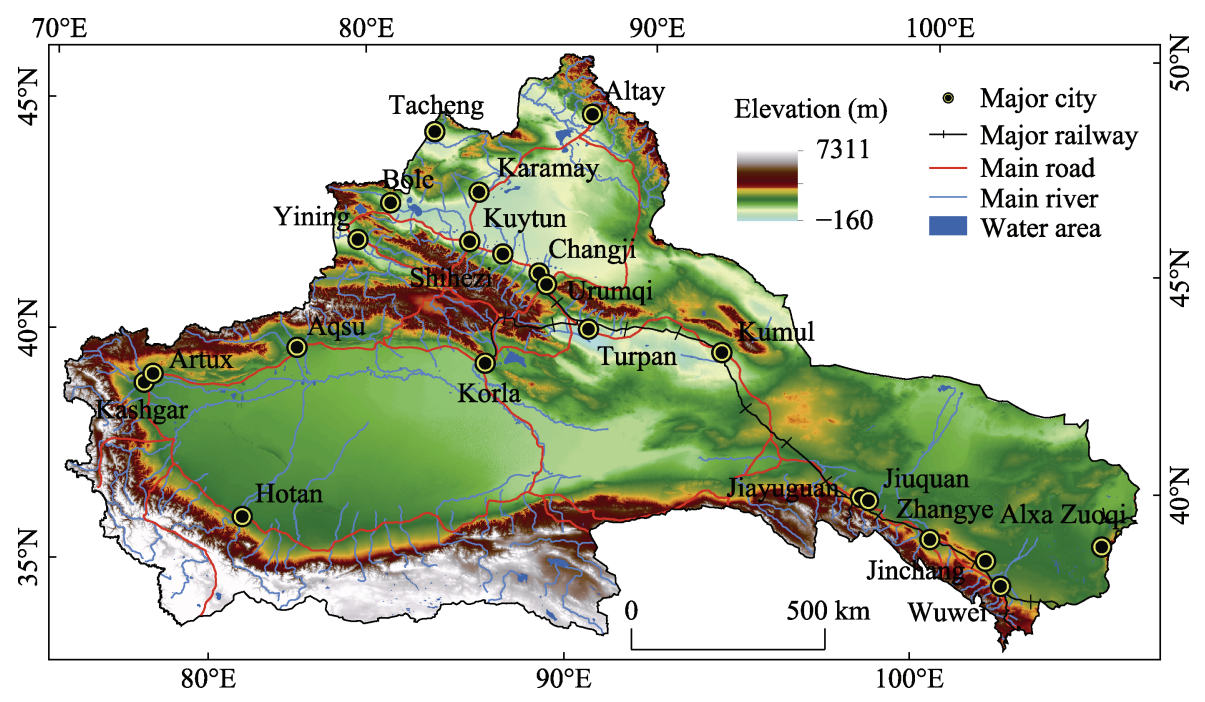

Figure 1 Map and elevation of northwest China 


\subsection{Data sources and processing}

Multiple sources of data were used in this study as follows.

(1) MOD13A3 products of Moderate Resolution Imaging Spectroradiometer (MODIS) data (normalized difference vegetation index (NDVI) data, temporal resolution of product was month and spatial resolution was $1 \mathrm{~km}$ ) and MOD11A2 products of land surface temperature (LST) data (temporal resolution of 8 days and spatial resolution of $1 \mathrm{~km}$ ) from the National Aeronautics and Space Administration Level-1 and Atmosphere Archive \& Distribution System Distributed Active Archive Center website (https://ladsweb.modaps.eosdis. nasa.gov) were used. The row and column numbers of the data were h23v04, h23v05, $\mathrm{h} 24 \mathrm{v} 04, \mathrm{~h} 24 \mathrm{v} 05, \mathrm{~h} 25 \mathrm{v} 04, \mathrm{~h} 25 \mathrm{v} 05, \mathrm{~h} 26 \mathrm{v} 04$ and h26v05. Because the MODIS image data in 2000 were missing in January, and the image quality in other months was relatively poor, this study used the MODIS data in 2001 to replace the data in 2000. The preprocessing process was as follows: after projection conversion, image splicing and maximum value synthesis, the temporal and spatial resolutions of LST data were processed to be consistent with NDVI data, and then the monthly data were batch cut and mean value processed using Python language to obtain the annual data (Zhang, 1994; Wei et al., 2014; Sun et al., 2015).

(2) The digital elevation model (DEM) was from the geospatial data cloud platform (http://www.gscloud.cn), with a spatial resolution of $90 \mathrm{~m}$.

(3) Soil data were from the Harmonized World Soil Database (http://www.fao.org) and the Data Center for Resources and Environmental Sciences of the Chinese Academy of Sciences (http://www.resdc.cn).

(4) The land use/cover data were from the Data Center for Resources and Environmental Sciences of the Chinese Academy of Sciences (http://www.resdc.cn). As there were no data on land-use/cover type in the study area in 2017, and the conversion rate between land use/cover types was not large within two years (Wei et al., 2014; Bi et al., 2017), the data for 2015 were used instead for 2017. This did not affect the accuracy of this study.

(5) The river data were from the 1:4 million China Fundamental Geographic Database of the National Fundamental Geographic Information Center (http://www.ngcc.cn).

(6) The meteorological station data were from the monthly dataset of China's surface climate data of China Meteorological Data Network (http://data.cma.cn).

(7) The vegetation data were from the Data Center for Resources and Environmental Sciences of the Chinese Academy of Sciences (http://www.resdc.cn).

(8) The social and economic data were mainly from the CNKI China Economic and Social Big Data Research platform (http://data.cnki.net). Some missing data were supplemented by the economic and social statistics bulletins of Gansu Province, Inner Mongolia Autonomous Region and Xinjiang Uygur Autonomous Region in corresponding years. In addition, the spatial resolution of all indices obtained and calculated from various data was unified into a grid format of $1 \mathrm{~km} \times 1 \mathrm{~km}$, and Krasovsky ellipsoid coordinates and Albers projection were used (Zhai, 2011; Yang, 2017; Xu et al., 2019).

\subsection{Selection of indicator factors}

Desertification is a complex and changeable process affected by multiple factors. Interactions between natural and human indices lead to changes in regional climate, hydrology, soil, 
vegetation and topography, which influence and determine the changing trends, characteristics and heterogeneity of the spatial and temporal distributions. The interactions are shown in Figure 2. In arid northwest China, there are three key factors that affect the topographic and geomorphic features - elevation, slope and aspect - which restrict the distribution and accumulation of desertified land (Xu et al., 2011; Amani et al., 2017; Mesquita et al., 2017). Some indicator factors such as geomorphic type, climatic characteristics, hydrothermal conditions and human activities at different altitude gradients have different influences on regional vegetation cover and biodiversity, which directly affect desertification (Cui et al., 2011; Yang, 2017). Differences in solar radiation, precipitation evaporation, soil and water conservation capacity, and vegetation cover on sunny and shady slopes will all lead to spatial differentiation of land desertification. The soil environment, such as soil organic matter, soil texture and soil erosion intensity, is the decisive factor, which directly affects the degree and change of desertification. The content of soil organic matter is a typical representative index reflecting the physical and chemical properties of soil, and is an indispensable basic condition for the growth and development of vegetation (Duan et al., 2018; Shi et al., 2018). Different degrees of soil erosion intensity have different impacts on desertification. For example, soil erosion in northwest China is mainly caused by wind, which can cause erosion, transformation and deposition of soil particles, resulting in soil coarsening and desertification (Wang et al., 2018; Wei et al., 2019; Zhou et al., 2019). Moreover, hydrological elements such as water resources, rivers, lakes and reservoirs are lifelines in arid areas, determining vegetation growth and size of biomass. The amount of water resources, including surface water and groundwater, indirectly restricts the process and expansion of land desertification (Zhu et al., 2016; Xu et al., 2019). The surface water resources of the arid region in northwest mainly come from glacial meltwater, rivers, ditches, lakes and reservoirs, which are the main water resources and support the survival and development of the entire arid region (Wang et al., 2019; Zhou et al., 2019).

Climate conditions are key factors in the evolution of desertification in the arid region of northwest China. Regional dryness degree and LST can comprehensively reflect the contradictory relationship between regional precipitation and evapotranspiration as well as hydrothermal balance. The higher the dryness degree and surface temperature, the greater the pressure the ecosystem bears and the higher the sensitivity of desertification. Wind power affects the degree of soil erosion and is the source power of soil desertification (Liu et al., 2007; Zhu et al., 2016; Zhou et al., 2019). Vegetation coverage has an obvious inhibitory effect on the process of land desertification expansion. Different regional areas of vegetation coverage and drought resistance have different responses to drought and desertification. Different types of vegetation in the arid region can promote improvement of regional climate, soil, geology and other conditions, while directly preventing desertification increase (Wang et al., 2017; Yang, 2017; Zhao et al., 2018). Vegetation types of trees, shrubs and gramineous plants play a good ecological role in windbreaking and sand fixation, water conservation, climate regulation and other eco-functions, and also retard the process of land desertification and reduce the sensitivity to desertification. All of the indicator factors are important for evaluation of desertification sensitivity, especially for arid regions in China.

Therefore, based on the principles of scientificity, comprehensiveness, independence and operability, and 15 factors were selected from the five aspects of topography, soil, hydrology, 
climate and vegetation, to construct an evaluation system for a desertification sensitivity monitor (Table 1). The multivariate collinearity diagnosis for the 15 indices was calculated to check for information redundancy (Wei et al., 2020). It was found that the variance inflation factors of the selected indices were all less than 10, the tolerances were all greater than 0.1 and there was no obvious collinearity (Ma et al., 2018; Wang et al., 2019). Therefore, the proposed evaluation index system is feasible to study desertification sensitivity in this paper.

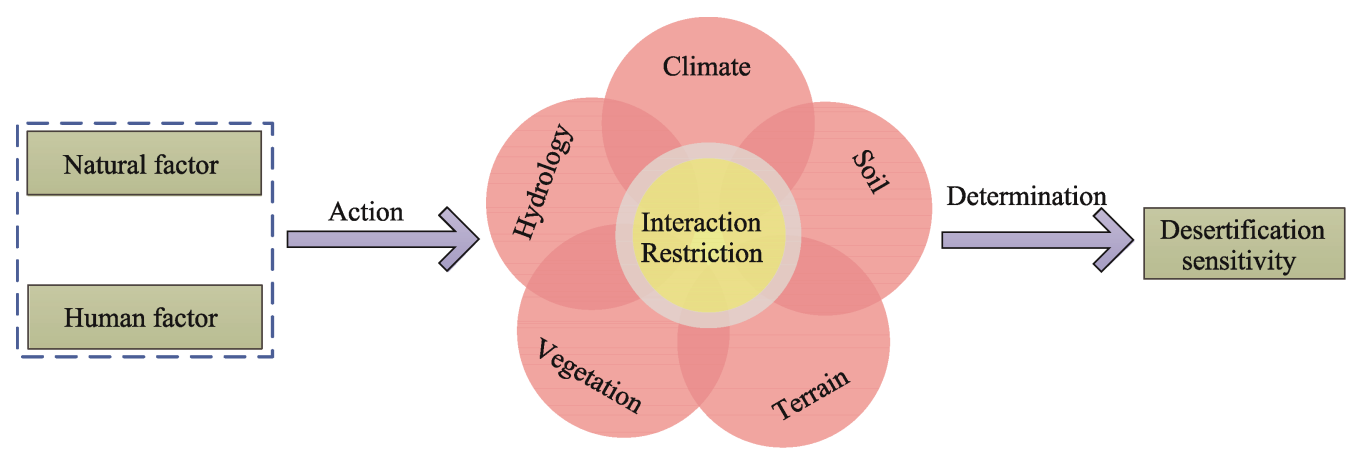

Figure 2 Analysis of the principle of desertification sensitivity

Table 1 Evaluation index system of desertification sensitivity

\begin{tabular}{lll}
\hline \multicolumn{1}{c}{ Primary indicator } & \multicolumn{1}{c}{ Secondary indicator layer } & Standardized treatment \\
\hline Terrain background index (TBI) & Elevation & - \\
& Slope & + \\
& Aspect & - \\
Soil background index (SBI) & Soil organic matter content & + \\
& Soil erosion intensity & + \\
& Soil depth & + \\
Hydrological background index & Gravel content of soil & + \\
(HBI) & Distance from glacier and snow & + \\
& Distance from major rivers & - \\
Climatic background index (CBI) & Distance from lakes and reservoirs & + \\
& Degree of dryness & + \\
Vegetation background index (VBI) & LST & - \\
\hline
\end{tabular}

Note: + represents positive normalization, - represents negative normalization.

\subsection{Desertification sensitivity evaluation model}

\subsubsection{Spatial distance model (SDM)}

Traditional methods such as linear weighting, geometric average weighted and linear weighted sum cannot accurately describe the mutual influence and restriction on desertification sensitivity because of the complex processes and subjective weight determination in- 
volved (Amani et al., 2017; Mesquita et al., 2017; Wei et al., 2019; Wei et al., 2020). The Euclidean distance measure method has recently been widely used to evaluate the effect of different indicator factors in change processes and characteristics because of the objectivity, scientificity and universality of the theory. The formula used is:

$$
D(X, Y)=\sqrt{\sum_{i=1}^{n}\left(x_{i}-y_{i}\right)^{2}}
$$

where $D(X, Y)$ is the Euclidean distance between $X\left(x_{1}, x_{2}, x_{3}, \ldots, x_{n}\right)$ and $Y\left(y_{1}, y_{2}, y_{3}, \ldots, y_{n}\right)$, and $n$ is the dimension of the multidimensional space.

Euclidian distance has been widely used in various fields such as drought detection, agricultural sustainable development (Mesquita et al., 2017), ecological and environmental quality assessment (Amani et al., 2017) and rocky desertification identification (Wei et al., 2019). Therefore, based on the principles of the Euclidean distance and geographic information system, an SDM was proposed to evaluate the desertification sensitivity in this study. The SDM is based on Euclidean distance and measurement of the multidimensional space of the absolute distance between each factor. It can exactly monitor the spatiotemporal changes (Amani et al., 2017; Wei et al., 2019; Wei et al., 2020). The minimum benchmark is defined in multidimensional space based on the research objective, the dimension that has the lowest sensitivity level, and then by calculating the Euclidean distance between each multidimensional point and the minimum benchmark point. The degree of spatial desertification sensitivity is judged from the size of the Euclidean distance. The greater the calculated distance value, the higher the sensitivity of land desertification. The formula is:

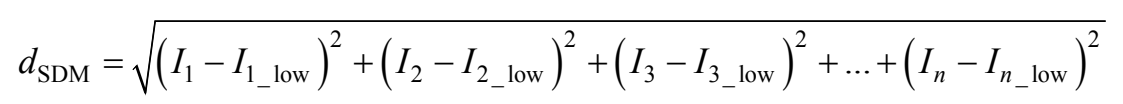

where $d_{\mathrm{SDM}}$ is the Euclidean distance from each point to the reference point in multidimensional space, $I_{n}$ is the dimension of multidimensional space and $\left(I_{1}, I_{2}, I_{3}, \ldots, I_{n}\right)$ are points in the multidimensional space.

\subsubsection{Desertification sensitivity index (DSI)}

In this study, the SDM was used to calculate the desertification sensitivity by integrating the five aspects of TBI, SBI, HBI, CBI and VBI and constructing a DSI according to the principles of the SDM. TBI, SBI, HBI, CBI and VBI were also calculated according to the Euclidean distance principle. The formulae are shown in Table 2. Each index was standardized using the extremum method to remove the influence on the evaluation result caused by different units. The calculation formula for DSI is:

DSI $=$

$$
\sqrt{\left(\mathrm{TBI}-\mathrm{TBI}_{\mathrm{low}}\right)^{2}+\left(\mathrm{SBI}-\mathrm{SBI}_{\mathrm{low}}\right)^{2}+\left(\mathrm{HBI}-\mathrm{HBI}_{\mathrm{low}}\right)^{2}+\left(\mathrm{CBI}-\mathrm{CBI}_{\mathrm{low}}\right)^{2}+\left(\mathrm{VBI}-\mathrm{VBI}_{\mathrm{low}}\right)^{2}}
$$

where TBI, SBI, HBI, CBI and VBI are the topographic background index, soil background index, hydrological background index, climatic background index and vegetation background index, respectively. The calculated indices are shown in Table $2 . \mathrm{TBI}_{\text {low }}, \mathrm{SBI}_{\text {low }}$, $\mathrm{HBI}_{\text {low }}, \mathrm{CBI}_{\text {low }}$ and $\mathrm{VBI}_{\text {low }}$ are the lowest reference points, comprising the minimum value of each background index. 
Table 2 Construction method of each background index

\begin{tabular}{|c|c|c|}
\hline $\begin{array}{c}\text { Single } \\
\text { background index }\end{array}$ & Calculating formula & Explanation \\
\hline $\begin{array}{c}\text { Topographic } \\
\text { background index }\end{array}$ & $\mathrm{TBI}=\sqrt{\begin{array}{l}\left(E-E_{\mathrm{low}}\right)^{2}+ \\
\left(S-S_{\mathrm{low}}\right)^{2}+ \\
\left(A-A_{\mathrm{low}}\right)^{2}\end{array}}$ & $\begin{array}{l}E, S \text { and } A \text { are the altitude, slope and aspect factors, respec- } \\
\text { tively; } E_{\text {low }}, S_{\text {low }} \text { and } A_{\text {low }} \text { are the lowest values of sensitivity } \\
\text { represented by the three-dimensional space composed of alti- } \\
\text { tude, slope and aspect, respectively. The reference point }\left(E_{\text {low }} \text {, }\right. \\
\left.S_{\text {low }}, A_{\text {low }}\right) \text { is }(0,0,0) \text {. The higher the TBI value, the higher the } \\
\text { sensitivity of land desertification at the terrain factor level. } \\
\text { Elevation (in meters) is directly obtained based on the DEM, } \\
\text { while slope and aspect are extracted with the ArcGIS10.2 Slope } \\
\text { and Aspect tool. Aspect was ranked from low sensitivity to high } \\
\text { sensitivity as follows: flat land }<\text { west, northwest and north }< \\
\text { northeast and east }<\text { southeast, south and southwest, with values } \\
\text { ranging from } 1 \text { to } 4 \text {. }\end{array}$ \\
\hline $\begin{array}{l}\text { Soil background } \\
\text { index }\end{array}$ & $\mathrm{SBI}=\sqrt{\begin{array}{c}\left(\mathrm{SOMC}-\mathrm{SOMC}_{\mathrm{low}}\right)^{2}+ \\
\left(\mathrm{SEI}-\mathrm{SEI}_{\mathrm{low}}\right)^{2}+ \\
\left(\mathrm{SSC}-\mathrm{SSC}_{\mathrm{low}}\right)^{2}+ \\
\left(\mathrm{SD}-\mathrm{SD}_{\mathrm{low}}\right)^{2}\end{array}}$ & $\begin{array}{l}\mathrm{SOMC}, \mathrm{SEI}, \mathrm{SSC} \text { and } \mathrm{SD} \text { are soil organic matter content, soil } \\
\text { erosion intensity, soil sand content and soil depth, respectively. } \\
\text { The reference point }\left(\mathrm{SOMC}_{\text {low }}, \mathrm{SEI}_{\text {low }}, \mathrm{SSC}_{\text {low }}, \mathrm{SD}_{\text {low }}\right) \text { is }(0,0,0 \text {, } \\
0) \text {. The soil organic matter content was converted into a per- } \\
\text { centage by dividing the soil organic carbon in the world soil } \\
\text { database by } 0.58 \text {. Soil erosion intensity was rated as } 1-6 \text { ac- } \\
\text { cording to the following erosion types: micro erosion, light } \\
\text { erosion, moderate erosion, intense erosion, extreme intense } \\
\text { erosion and severe erosion. The soil sand content was directly } \\
\text { provided by the Data Center of Resources and Environmental } \\
\text { Sciences. Soil depth was quantified according to soil type. }\end{array}$ \\
\hline $\begin{array}{c}\text { Hydrological } \\
\text { background index }\end{array}$ & $\mathrm{HBI}=\sqrt{\begin{array}{l}\left(\mathrm{DS}-\mathrm{DS}_{\mathrm{low}}\right)^{2}+ \\
\left(\mathrm{DR}-\mathrm{DR}_{\mathrm{low}}\right)^{2}+ \\
\left(\mathrm{DLR}-\mathrm{DLR}_{\mathrm{low}}\right)^{2}\end{array}}$ & $\begin{array}{l}\mathrm{DS}, \mathrm{DR} \text { and DLR are the distance from glaciers and snow, } \\
\text { distance from major rivers, and distance from lakes and reser- } \\
\text { voirs, respectively. The reference point }\left(\mathrm{DS}_{\text {low }}, \mathrm{DR}_{\text {low }}, \mathrm{DLR}_{\text {low }}\right) \\
\text { is }(0,0,0) \text {. The higher the HBI value, the lower the regional } \\
\text { water resource quantity, and the higher the sensitivity of land } \\
\text { desertification. The distances from glaciers and snow, major } \\
\text { rivers, and lakes and reservoirs were calculated using the } \\
\text { Euclidean distance tool in ArcGIS10.2. }\end{array}$ \\
\hline $\begin{array}{l}\text { Climatic background } \\
\text { index }\end{array}$ & $\begin{array}{c}\mathrm{AI}=\frac{P}{t^{0}+10} \mathrm{CBI}= \\
\sqrt{\begin{array}{c}\left(\mathrm{AWV}-\mathrm{AWV}_{\mathrm{low}}\right)^{2}+ \\
\left(\mathrm{AI}-\mathrm{AI}_{\mathrm{low}}\right)^{2}+ \\
\left(\mathrm{LST}-\mathrm{LST}_{\text {low }}\right)^{2}\end{array}}\end{array}$ & $\begin{array}{l}\text { AI, } P \text { and } t^{0} \text { are dry degree, annual average precipitation and } \\
\text { annual average temperature, respectively. AWV and LST are } \\
\text { mean wind speed and land surface temperature, respectively. } \\
\text { The reference point ( } \mathrm{AWV}_{\text {low }}, \mathrm{AI}_{\text {low }}, \mathrm{LST}_{\text {low }} \text { ) is }(0,0,0) \text {. The } \\
\text { higher the CBI value, the higher the sensitivity of land deserti- } \\
\text { fication. The surface temperature came from the MODIS data } \\
\text { product, and the dryness and average wind speed were provided } \\
\text { by } 112 \text { meteorological stations in the research area and sur- } \\
\text { rounding areas. The spatial distribution map was obtained by } \\
\text { Kriging interpolation. Average wind speed can be directly ob- } \\
\text { tained from the meteorological dataset. }\end{array}$ \\
\hline $\begin{array}{c}\text { Vegetation } \\
\text { background index }\end{array}$ & $\mathrm{VBI}=\sqrt{\begin{array}{c}\left(\mathrm{NDVI}-\mathrm{NDVI}_{\mathrm{low}}\right)^{2}+ \\
\left(\mathrm{DR}-\mathrm{DR}_{\mathrm{low}}\right)^{2}\end{array}}$ & $\begin{array}{l}\text { NDVI and DR are normalized vegetation index and drought } \\
\left.\text { resistance of vegetation. The reference point (NDVI } I_{\text {low }} \text {, DR } \text { low }_{\text {low }}\right) \\
\text { is }(0,0) \text {. The higher the VBI value, the lower the vegetation } \\
\text { cover and the higher the desertification sensitivity. The NDVI } \\
\text { was derived from MODIS data products, and vegetation } \\
\text { drought resistance ability was based on quantitative extraction } \\
\text { of vegetation types, according to the desertification sensitivity } \\
\text { from low to high: needle broad-leaved forest, coniferous forest, } \\
\text { broad-leaved mixed forest and water }<\text { marshes, planting vege- } \\
\text { tation, alpine vegetation and thickets }<\text { grassland, meadow and } \\
\text { pasture and grass }<\text { desert, rock and vegetation coverage, with } \\
\text { values ranging from } 1 \text { to } 4 \text {. }\end{array}$ \\
\hline
\end{tabular}

To compare and analyze the spatial distribution characteristics of desertification sensitivity in different periods, the natural breaks (Jenks) method was used to classify the evaluation results. The classification standard of spatial distribution of desertification sensitivity was 
unified according to the regional characteristics of arid northwest China and some research results (Ma et al., 2018; Xu et al., 2019; Zhou et al., 2019). The classification standards are shown in Table 3.

Table 3 Classification standards for desertification sensitivity in northwest China

\begin{tabular}{ccc}
\hline Category & Sensitivity & Range \\
\hline 1 & Nonsensitive & $<1.561$ \\
2 & Slightly sensitive & $1.561-1.842$ \\
3 & Moderately sensitive & $1.842-2.131$ \\
4 & Highly sensitive & $2.131-2.386$ \\
5 & Extremely sensitive & $\geqslant 2.386$ \\
\hline
\end{tabular}

\subsection{Spatial and temporal evolution characteristics of desertification sensitivity}

\subsubsection{Conversion characteristics of desertification sensitivities in different periods}

To identify the change characteristics of different desertification sensitivities from 2000 to 2017, each sensitivity of raster cell was separately extracted based on the con function of the raster calculator in ArcGIS 10.4 software, and assigned a value of 1; a value of 0 was assigned for other raster cells. The raster maps of desertification sensitivities in different years were overlaid to analyze the conversion characteristics. Then, raster plots of the same sensitivity category for different years were presented, using the spatiodynamic pattern of each sensitivity type. The calculation formula is:

$$
\operatorname{code}_{i}=1000 \times \operatorname{code}_{i_{-} 2000}+100 \times \operatorname{code}_{i_{-} 2005}+10 \times \operatorname{code}_{i_{-} 2010}+1 \times \operatorname{code}_{i_{-} 2017}
$$

where $\operatorname{code}_{i}$ is the change code of each sensitivity type from 2000 to 2017, and code $i_{-2000}$, $\operatorname{code}_{i_{-2005}}, \operatorname{code}_{i_{-2010}}$ and code $_{i_{-2017}}$ represent the original code (0 or 1) in 2000, 2005, 2010 and 2017, respectively. According to the statistical code, there were 16 types of change codes, which were classified into seven categories of stable type, continuously increasing type, continuously decreasing type, fluctuating type, increasing fluctuating type, decreasing fluctuating type and other type. The type names and classification codes are shown in Table 4.

Table 4 Classification of each sensitivity conversion type

\begin{tabular}{|c|c|c|c|}
\hline Conversion type & Code & Value & Description \\
\hline Stable type & 1111 & 1 & $\begin{array}{l}\text { Type of desertification sensitivity did not change from } \\
2000 \text { to } 2017\end{array}$ \\
\hline Continuously increasing type & $0001,0111,0011$ & 2 & $\begin{array}{l}\text { This sensitivity type was increased by other type } \\
\text { conversions }\end{array}$ \\
\hline Continuously decreasing type & $1000,1100,1110$ & 3 & This sensitivity type was decreased because of conversion \\
\hline Fluctuating type & $\begin{array}{l}0010,0100,0110 \\
1001,1011,1101\end{array}$ & 4 & $\begin{array}{l}\text { The desertification sensitivity fluctuated irregularly from } \\
2000 \text { to } 2017\end{array}$ \\
\hline Increasing fluctuating type & 0101 & 5 & This displayed an increasing trend from 2000 to 2017 \\
\hline Decreasing fluctuating type & 1010 & 6 & This displayed a decreasing trend from 2000 to 2017 \\
\hline Other type & 0000 & 0 & There was no regular change \\
\hline
\end{tabular}

2.5.2 Conversion characteristics of desertification sensitivities in different sensitivity types Spatially superimposed raster maps of the five types of desertification sensitivity conversion types (nonsensitive, slightly sensitive, moderately sensitive, highly sensitive and extremely 
sensitive) were used to obtain overall desertification sensitivity types in the northwest arid region from 2000 to 2017 . The calculation formula is:

code $=10000 \times$ code $_{\text {non }}+1000 \times$ code $_{\text {slight }}+100 \times$ code $_{\text {moderate }}+10 \times \operatorname{code}_{\text {high }}+1 \times \operatorname{code}_{\text {extreme }}$

where code is the code for mutual conversion of desertification sensitivity types from 2000 to 2017 ; code $_{\text {none }}, \operatorname{codes}_{\text {light }}$, code moderate,, code $_{\text {high }}$ and code $_{\text {extreme }}$ are the raster images converted from the above five types of sensitivity (nonsensitive, slightly sensitive, moderately sensitive, highly sensitive and extremely sensitive), respectively. The attribute is (0-6). There are 25 types of code, which can be used to extract the overall conversion type of desertification sensitivity in the arid region of northwest China (Table 5).

Table 5 Classification table of conversion types of desertification sensitivity assignment codes and their meaning

\begin{tabular}{|c|c|c|}
\hline Assignment & Code & Meanings \\
\hline 1 & 00001 & Sensitivity type has always been extremely sensitive \\
\hline 2 & 00010 & Sensitivity type has always been highly sensitive \\
\hline 3 & 00023,00056 & Sensitivity type changed from extremely sensitive to highly sensitive \\
\hline 4 & 00044 & Sensitivity type fluctuated between extremely sensitive and highly sensitive \\
\hline 5 & 00032,00065 & Sensitivity type reversed from highly sensitive to extremely sensitive \\
\hline 6 & 00100 & Sensitivity type has always been moderately sensitive \\
\hline 7 & 00230,00560 & Sensitivity type changed from highly sensitive to moderately sensitive \\
\hline 8 & 00440 & Sensitivity type fluctuated between highly sensitive and moderately sensitive \\
\hline 9 & 00320,00650 & Sensitivity type reversed from moderately sensitive to highly sensitive \\
\hline 10 & 01000 & Sensitivity type has always been slightly sensitive \\
\hline 11 & 02300,05600 & Sensitivity type changed from moderately sensitive to slightly sensitive \\
\hline 12 & 04400 & Sensitivity type fluctuated between moderately sensitive and slightly sensitive \\
\hline 13 & 03200,06500 & Sensitivity type reversed from slightly sensitive to moderately sensitive \\
\hline 14 & 10000 & Sensitivity has always been nonsensitive \\
\hline 15 & 23000,56000 & Sensitivity type changed from slightly sensitive to nonsensitive \\
\hline 16 & 44000 & Sensitivity type fluctuated between slightly sensitive and nonsensitive \\
\hline 17 & 32000,65000 & Sensitivity type reversed from nonsensitive to slightly sensitive \\
\hline
\end{tabular}

\subsection{Geographical detector method}

During the evolution of land desertification, as a result of the interaction of various factors, there will be obvious spatial differentiation characteristics. Identifying and analyzing the laws and driving factors of spatial differentiation is the cornerstone of controlling land desertification. The geographical detector method is a statistical method used to detect spatial heterogeneity and explore the multi-factor driving effect; it is widely used in nature, society, environment and other fields. In this study, the factor detector in the geographical detector method was used to study the different influential factors on the desertification sensitivity in the arid region of northwest China, which can be expressed by the $q$ value of the geographical detection force. The calculation formulae are: 


$$
\begin{gathered}
q=1-\frac{\sum_{h=1}^{L} N_{h} \sigma_{h}{ }^{2}}{N \sigma^{2}}=1-\frac{\mathrm{SSW}}{\mathrm{SST}} \\
\mathrm{SSW}=\sum_{h=1}^{L} N_{h} \sigma_{h}{ }^{2} \\
\mathrm{SST}=N \sigma^{2}
\end{gathered}
$$

where $h=1,2, \ldots, L$, which is the dependent variable $Y$ or the independent variable $X$ stratified classification; $N_{h}$ is the number of cells in layer $h$ in the whole region. $\Sigma h^{2}$ and $\sigma^{2}$ are the variance of $h$ and the $Y$ value of the dependent variables of the whole region, respectively. SSW and SST are the sum of layer variances and the total regional variance, respectively. The value of $q$ ranges between 0 and 1 . The larger the $q$ value, the greater the influence of this factor on the sensitivity of desertification.

\section{Results}

\subsection{Distribution characteristics of single background elements of desertification sen- sitivity}

Figure 3 shows the spatial distribution of various background elements in 2017. Figure 3a displays the spatial distribution of VBI, showing that the areas with high vegetation cover-
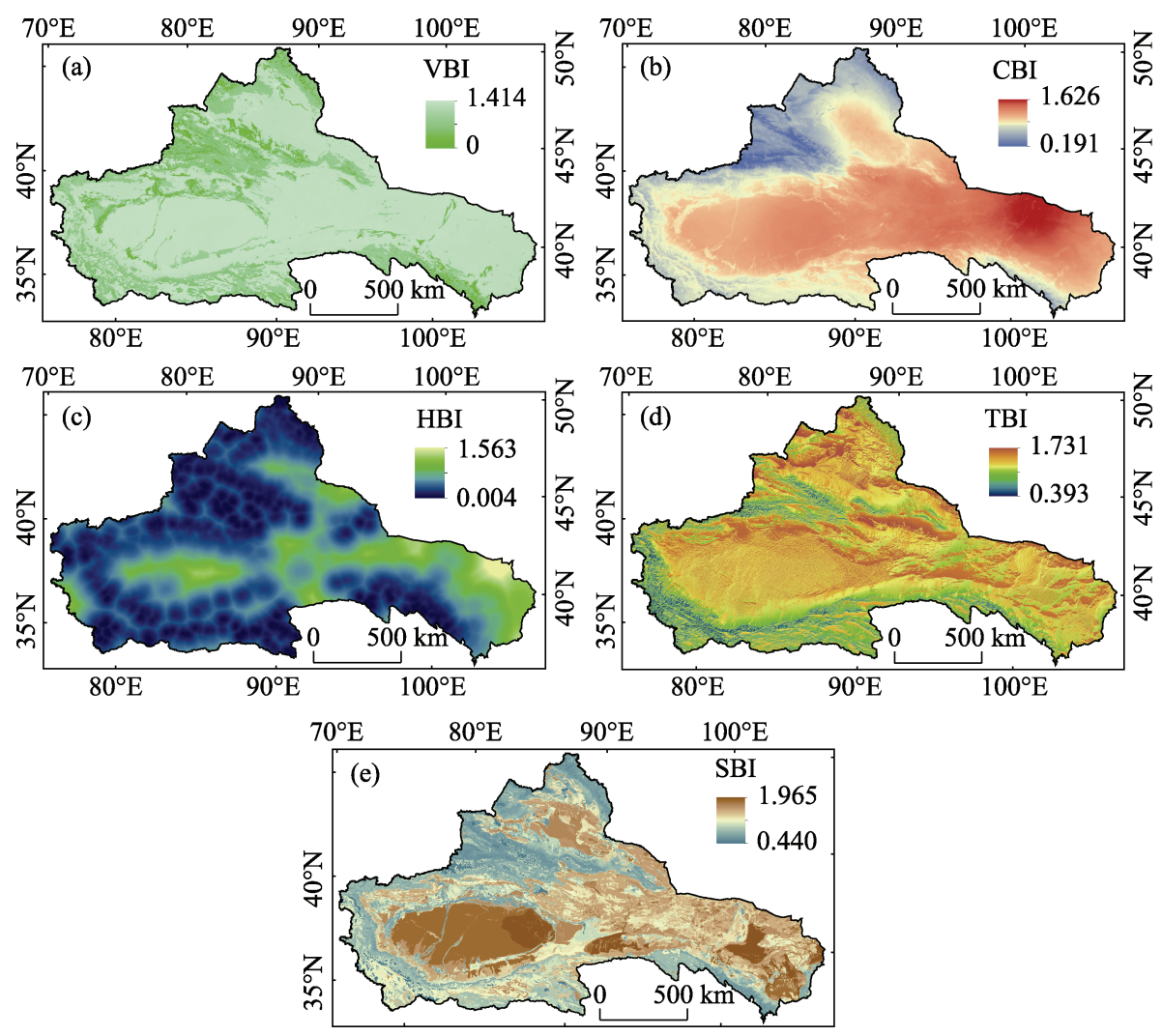

Figure 3 Spatial distribution maps of background elements in 2017 
age were mainly concentrated in the major mountain ranges and their surrounding oasis areas with high altitudes. The vegetation types were mostly trees, shrubs and herbaceous plants. These areas had a strong buffering capacity and resistance to drought. The average VBI values in 2000, 2005, 2010 and 2017 were 1.061, 1.052, 1.051 and 1.050, respectively, which showed a gradual increase in vegetation cover, and inhibition of desertification sensitivity was also gradually increased. Figure $3 \mathrm{~b}$ displays the spatial distribution of the climate background index CBI. The average values of CBI were higher than 1.4, which showed that the climatic conditions became worse from 2000 to 2017, especially in the Alxa region of Inner Mongolia. The influence of climate factors on desertification sensitivity was high. Figure 3c displays the spatial distribution of HBI. In recent years, the surface water resources reserves in northwest China have shown a tendency to increase slowly. The spatial distribution of hydrological elements is less sensitive to desertification near the water resources. Figures $3 \mathrm{~d}$ and $3 \mathrm{e}$ display the TBI and the SBI, respectively. The topography of the northwest arid region is undulating, and the types of landforms are diverse. The sensitivity of land desertification decreases with elevation and slope. In terms of spatial distribution, the terrain and soil environment of mountain ranges and oasis areas are superior to those of basins and plains.

\subsection{Spatial distribution characteristics of desertification sensitivity}

\subsubsection{Overall spatial distribution characteristics}

Figure 4 shows the spatial distribution of desertification sensitivity in the northwest arid region from 2000 to 2017 . The results show that the spatial distribution of desertification sensitivity in northwest China is low in the peripheral area, high in the interior area. The moderately sensitive areas are distributed around nonsensitive and moderately sensitive areas, while the moderately sensitive areas are surrounded by highly and extremely sensitive areas. The low-sensitive areas (including nonsensitive and slightly sensitive) are mainly distributed in the five mountain ranges of Altai, Tianshan, Kunlun, Altun and Qilian and the surrounding oasis areas. The high sensitivity areas (including high sensitivity and extreme sensitivity) are mainly located in the Junggar Basin, Tarim Basin and the Inner Mongolia Plateau and the hinterlands of the Taklimakan Desert, Badain Jaran Desert and Tengger Desert. By calculating the area proportion of each sensitivity type in different years, the results show that the area distribution of each sensitivity type varies greatly (Figure 5). The largest land area in northwest China is of the highly sensitivity type, which accounted for $55.57 \%, 54.20 \%, 53.35 \%$ and $53.29 \%$, respectively, in 2000, 2005, 2010 and 2017, where the coverage type was mainly rock desert (gobi), saline land and barren land. However, the surface of the extremely sensitive area was covered by sand and soil, with the vegetation coverage less than $5 \%$. The climatic conditions were harsh, and land desertification was serious, which was not easy to change. The low-sensitive areas in 2000, 2005, 2010 and 2017 accounted for 26.30\%, 27.67\%, 28.74\% and 28.79\%, respectively, showing an increasing trend overall. Because they were located in the mountain and oasis areas, vegetation grew well. As the climatic conditions were mild, moisture was sufficient, and grass coverage was high, so desertification was not prone to occur in these areas. 

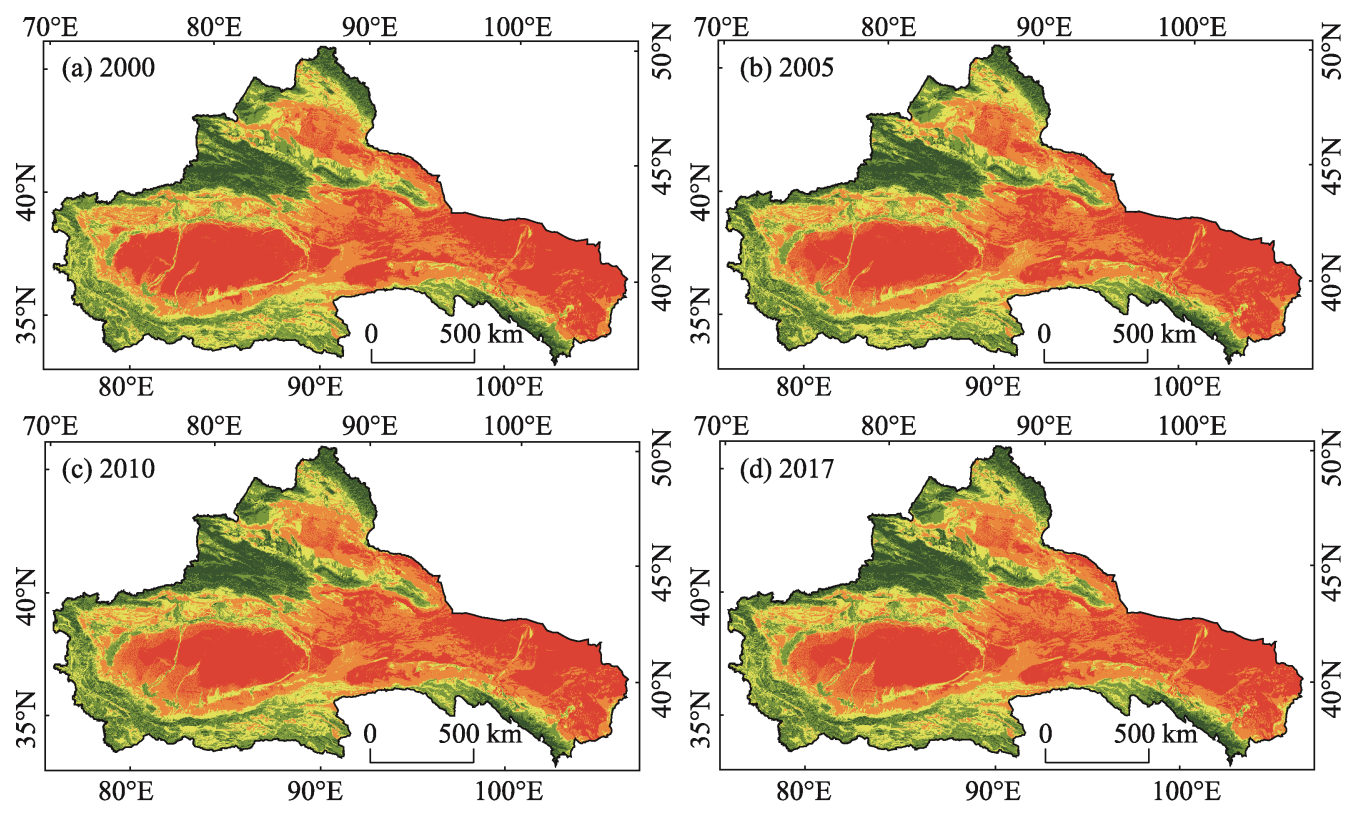

$\square$ Non-sensitivity $\square$ Slight sensitivity $\square$ Moderate sensitivity $\square$ High sensitivity $\square$ Extreme sensitivity

Figure 4 Spatial distribution of desertification sensitivity in northwest China

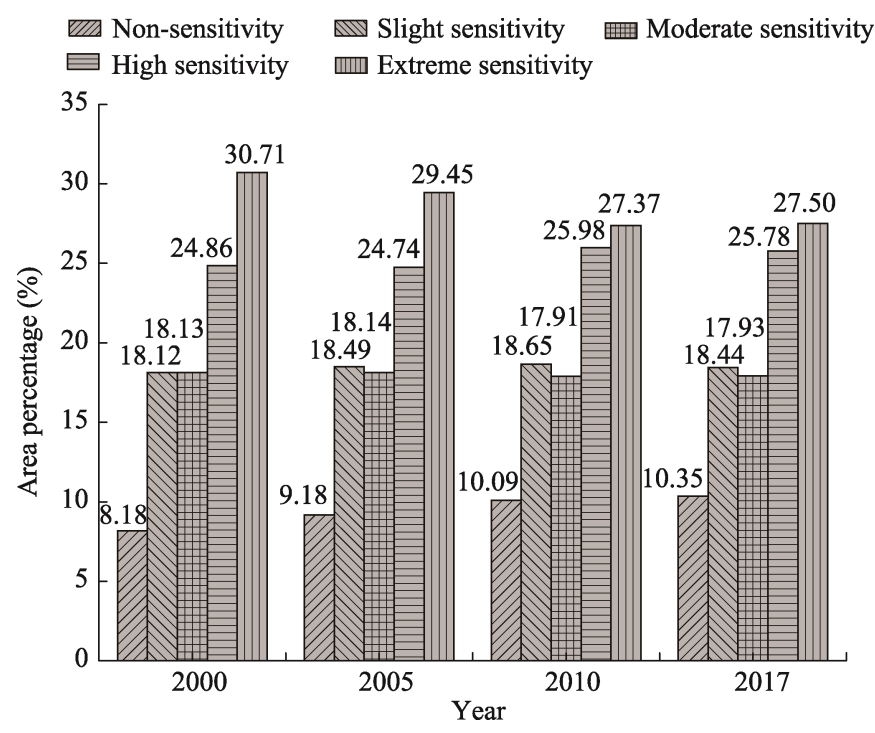

Figure 5 Area statistics of desertification sensitivity in northwest China

\subsubsection{Spatial distribution characteristics of sensitivity in typical regions}

The northwest arid region covered a large area, and the spatial and temporal distributions of regional desertification sensitivity were significantly different. Therefore, for the purposes of this study, 10 typical regions were selected for comparison and analysis (Figure 6). The results show that from 2000 to 2017, the sensitivity of regional desertification in eco-function protection area, agro-pastoral ecotone area, adjacent desert oasis area and oasis peripheral transitional area displayed a fluctuant reduction. The sensitivity of desertification 
in the Gobi Desert areas remained stable, at a highly sensitive and extremely sensitive level. For the eco-function protection area in the northwest arid region, because of the proactive protection policy, its vegetation, climate, soil, hydrology and other environment could be protected and improved, so the desertification sensitivity decreased significantly after 2010 . For the agro-pastoral ecotone area, the adjacent desert oasis area and the oasis peripheral transitional area, more attention has been paid to environmental protection and increasing investment in environmental protection in recent years; these were one of the main reasons for the desertification sensitivity decrease. For the Gobi Desert area, desertification was extremely serious, its climatic conditions were harsh, and the vegetation coverage and soil-water conservation ability were low. These were the main reasons for the high desertification sensitivity. The sensitivity of desertification has significant regional differences in spatial distribution, with clear boundaries and a concentrated distribution between high- and low-sensitivity areas.
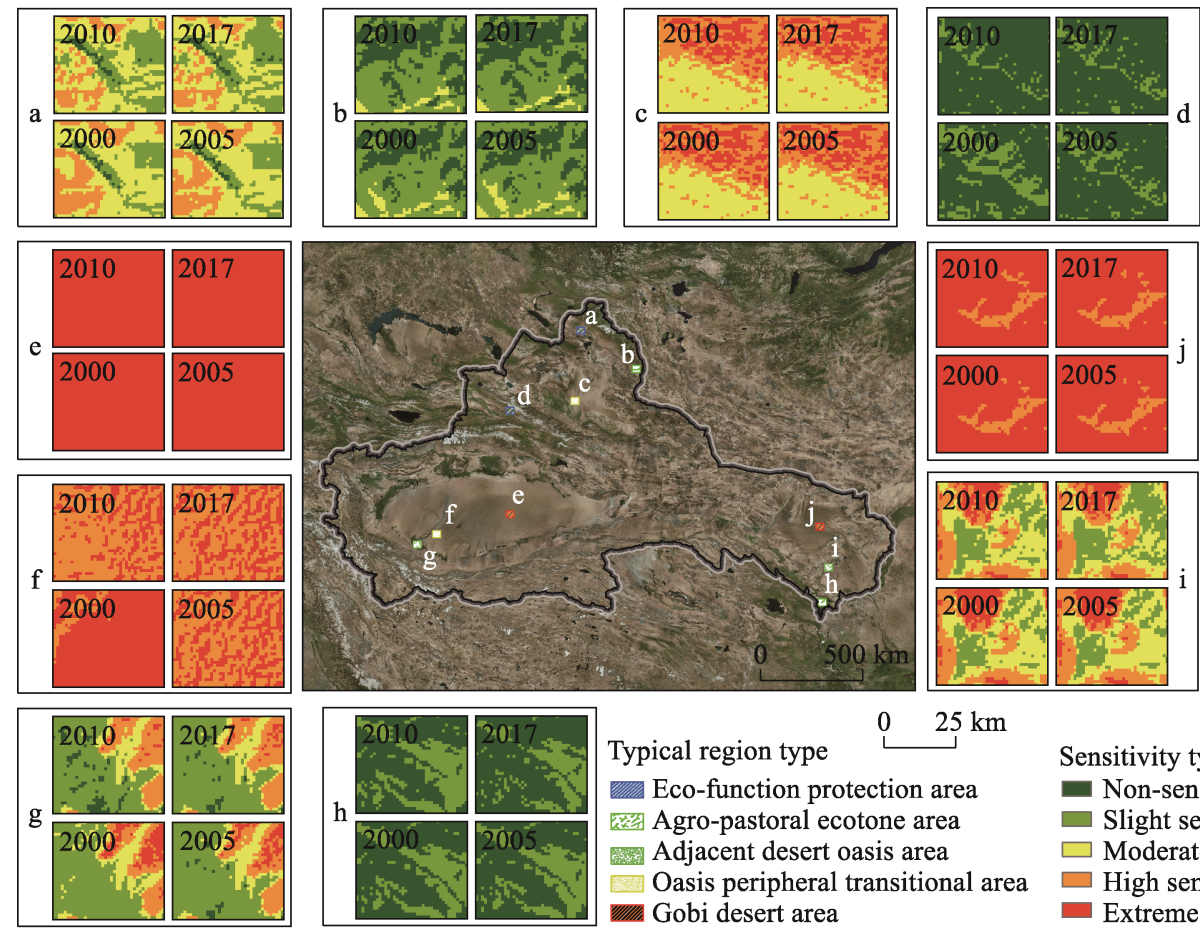

Typical region type $\stackrel{0}{25 \mathrm{~km}}$
Eco-function protection area
Agro-pastoral ecotone area
Odjacent desert oasis area
Oasis peripheral transitional area
Gobi desert area

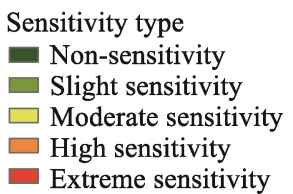

Figure 6 Spatial distributions of typical regions in northwest China. Note: This study selected typical regions from the northwest arid region for comparative analysis. Among them, a and $\mathrm{d}$ are eco-function protection areas located in Tianshan Mountains and Altai Mountains. b and h are the farming-pastoral ecotone located in Qinghe County and Tianzhu Tibetan Autonomous County. g and i are adjacent desert oasis areas located in Hotan Oasis and Minqin Oasis. e and $\mathrm{j}$ are located in the Gobi Desert area of Taklimakan Desert and Badain Jilin Desert. $c$ and $f$ are transitional areas around oases located in Urumqi and Hotan regions.

\subsection{Spatial and temporal evolution characteristics of desertification sensitivity}

3.3.1 Conversion characteristics of desertification sensitivities in different periods

Figure 7 shows the area statistics of each sensitivity type conversion from 2000 to 2017 . The 
results show that the main conversion type is the stable type. The area transfer in was greater than the transfer-out, except for the extremely sensitive type. The conversion characteristics were mainly a continuously increasing type and a fluctuating increase type $(24.901 \%$, $17.076 \%, 17.643 \%, 20.807 \%$ ), which was more than the decreasing type and fluctuant decrease type $(0.365 \%, 10.658 \%, 12.275 \%, 9.897 \%)$. The transfer-in area of the extremely sensitive area was smaller than that of the transfer-out area.

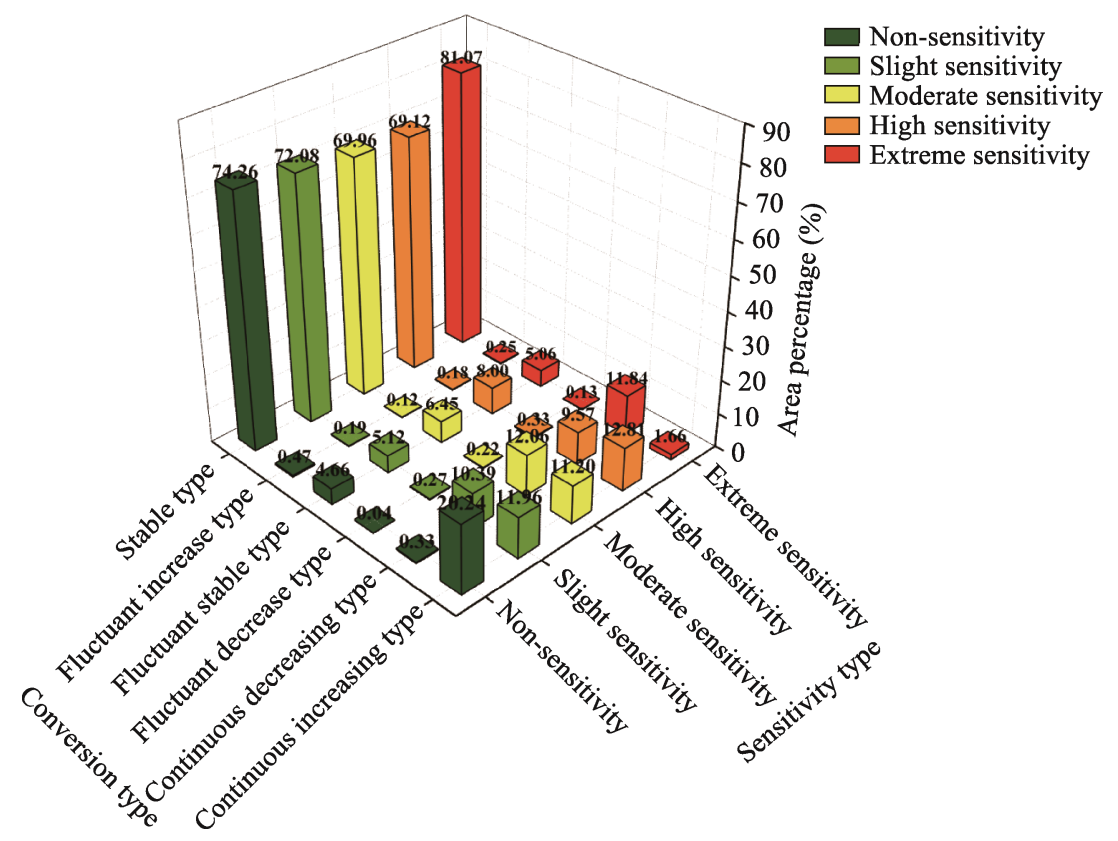

Figure 7 Area statistics of different conversion types of desertification sensitivity in northwest China

\subsubsection{Overall conversion characteristics in different sensitivity types}

The conversion characteristics of the sensitivity types can help to understand the transfer change status of each sensitivity type in and out, but it is difficult to judge the actual situation of the conversion between different sensitivity types. The overall conversion characteristics can be used to understand the change patterns with the aid of detailed conversion map. It is shown in Figure 8. The explanations and meanings of conversion types 1-17 are shown in Table 5. Figure 9 shows the conversion areas. The results show that from 2000 to 2017, the conversion area types 1,2, 6, 10 and 14 accounted for the largest proportion of land area $(84.81 \%)$. In the northwest arid region, the proportion of the land types with mutual conversion accounted for $15.19 \%$ of the total area. The proportions of land area converted from extremely sensitive to highly sensitive, highly sensitive to moderately sensitive, moderately sensitive to slightly sensitive and slightly sensitive to nonsensitive were $3.82 \%, 2.35 \%, 2.55 \%$ and $2.21 \%$, respectively, which indicated that the desertification sensitivity in northwest China showed a decreasing trend, and did not experience a sharp increase. 


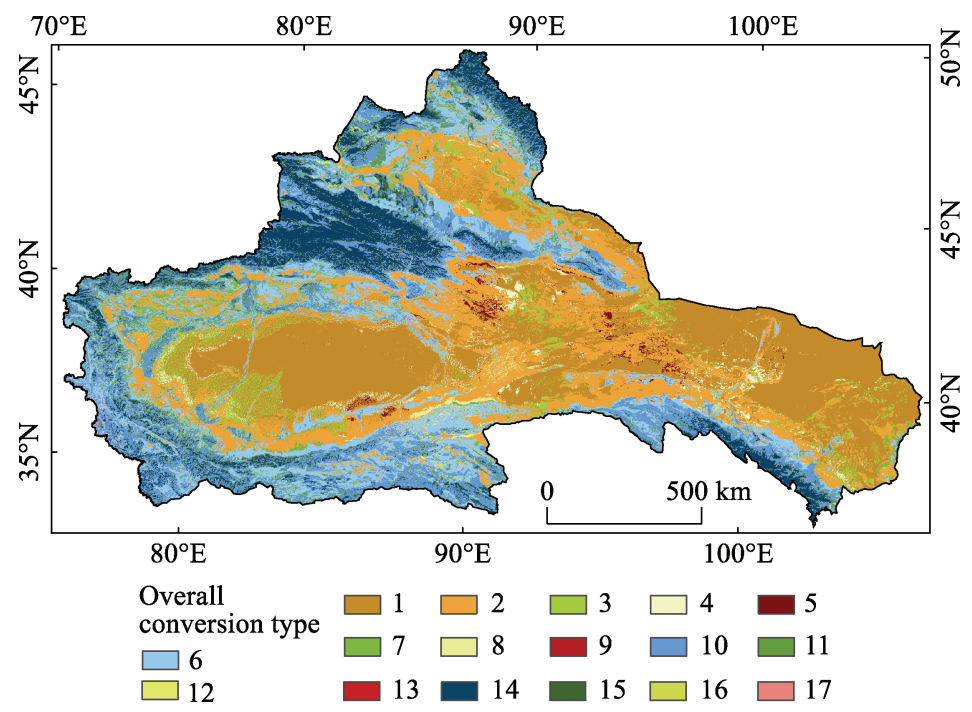

Figure 8 Spatial distribution of overall conversion types for desertification sensitivity in northwest China

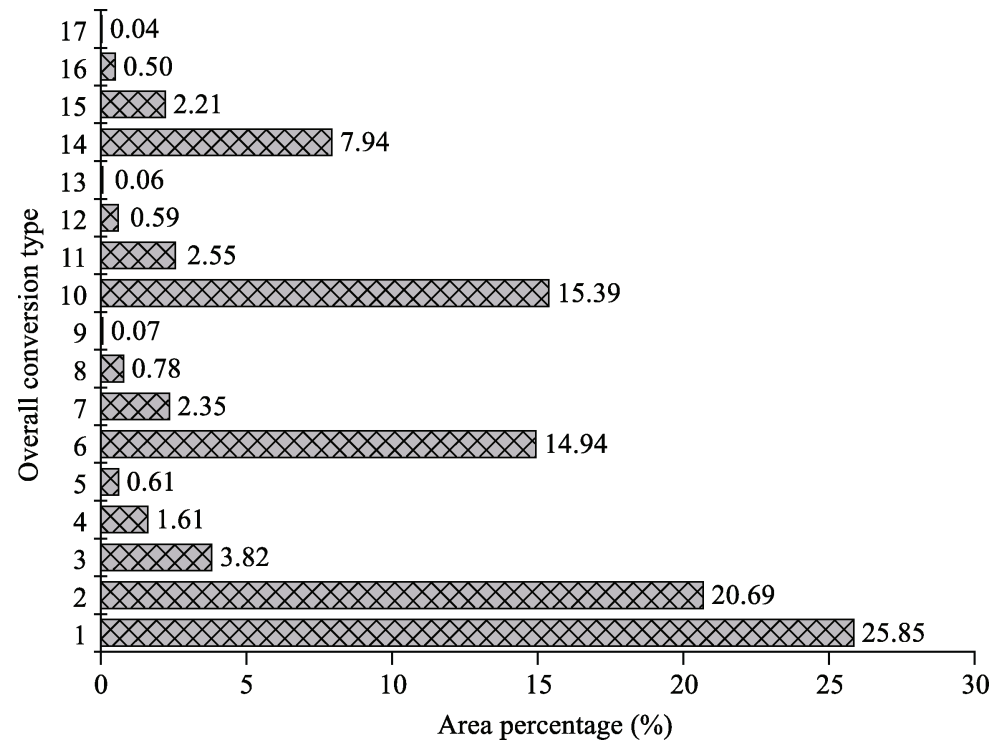

Figure 9 Area statistics of overall conversion types for desertification sensitivity in northwest China

\subsection{Analysis of influential factors of desertification sensitivity}

\subsubsection{Internal driving factors}

In this study, the factor detector model of the geographical detector was used to explore the effect of internal driving factors on desertification sensitivity in northwest China. The specific method was as follows: taking the DSI as the dependent variable, and the SBI, TBI, $\mathrm{CBI}, \mathrm{HBI}$ and VBI as independent variables, adopt the natural breakpoint method to stratify independent variables, convert numerical values into type quantity, adopt a uniform sampling method, obtain sufficient uniform sample points $(20,918$ points in total) in the research area by creating fishing net points of $10 \mathrm{~km} \times 10 \mathrm{~km}$, then extract the values of dependent 
variables and independent variables in different years for factor detection, respectively, and obtain the influence degree of each variable on desertification sensitivity. The results (Table 6) show that the influence of each background index on desertification sensitivity in different years was ranked by $q$ value size: $\mathrm{SBI}>\mathrm{CBI}>\mathrm{VBI}>\mathrm{HBI}>\mathrm{TBI}$. This demonstrates that in arid northwest China, soil and climate factors have the greatest influence on desertification sensitivity, followed by vegetation factors, while hydrology and terrain factors have the lowest influence. The $q$ values of the four years all have varying degrees of fluctuation, but the relative importance has not changed. In general, soil and climate played important roles in the succession process of internal driving factors affecting desertification in northwest China, and were the most important influential factors. Vegetation cover was the most active and basic factor to change desertification sensitivity, which means high vegetation cover played an important role in inhibiting sensitivity. In addition, the distribution of topography and changes in hydrology play a key role in restricting desertification sensitivity.

Table 6 Geographical detector method results of natural factors

\begin{tabular}{|c|c|c|c|c|c|c|c|c|}
\hline \multirow{2}{*}{ Primary indicator } & \multicolumn{2}{|c|}{2000} & \multicolumn{2}{|c|}{2005} & \multicolumn{2}{|c|}{2010} & \multicolumn{2}{|c|}{2017} \\
\hline & $q$ value & $p$ value & $q$ value & $p$ value & $q$ value & $p$ value & $q$ value & $p$ value \\
\hline SBI & 0.714 & $0.000^{* * *}$ & 0.710 & $0.000^{* * *}$ & 0.712 & $0.000^{* * *}$ & 0.715 & $0.000^{* * *}$ \\
\hline TBI & 0.311 & $0.000^{* * *}$ & 0.322 & $0.000^{* * *}$ & 0.308 & $0.000^{* * *}$ & 0.301 & $0.000^{* * *}$ \\
\hline CBI & 0.704 & $0.000^{* * *}$ & 0.710 & $0.000^{* * *}$ & 0.710 & $0.000^{* * *}$ & 0.711 & $0.000^{* * *}$ \\
\hline HBI & 0.435 & $0.000^{* * *}$ & 0.431 & $0.000^{* * *}$ & 0.433 & $0.000^{* * *}$ & 0.417 & $0.000^{* * *}$ \\
\hline VBI & 0.612 & $0.000^{* * *}$ & 0.610 & $0.000^{* * *}$ & 0.608 & $0.000^{* * *}$ & 0.609 & $0.000^{* * *}$ \\
\hline
\end{tabular}

Note: A significant $p$ value, when $p>0.10$, means that the significance test has not been passed. $* * *$ denotes $p<0.01$, which means the $1 \%$ significance test has been passed.

\subsubsection{Impact of social and economic development}

The population density, per capita gross domestic product (GDP) and the mean of the DSI for each county were calculated and correlation analysis was made using SPSS 23.0 software, the social and economic influence factors were analyzed and are shown in Table 7. The results show that there were no apparent consistent states (the correlation coefficient $r$ value was between -0.11 and -0.08 , and it did not pass the significance test) corresponding to a relationship between population density and desertification sensitivity. The arid region of northwest China is vast, with a low population base, and the influence of the population load is limited locally to the whole study area. The results show that the influence on desertification sensitivity is mainly caused by human activities to the surrounding environment, such as impact on vegetation and land cover, resulting in an increase in desertification sensitivity. For GDP per capita, the $r$ value increased gradually, and the $p$ value passed the significance test (2005 was 5\%, 2010 and 2017 were 1\%) except in 2000, which indicated that the impact of economic development on land desertification effect was increasing gradually and had a certain positive correlation. The correlation between economic development and land desertification was not significant, which indicated that the influence of economic development on the sensitivity of land desertification was limited to local areas and was not the main influential factor on desertification sensitivity in northwest China. 
Table 7 Correlation analyses of socio-economic factors and DSI

\begin{tabular}{|c|c|c|c|c|c|c|c|c|}
\hline \multirow{2}{*}{ DSI } & \multicolumn{2}{|c|}{2000} & \multicolumn{2}{|c|}{2005} & \multicolumn{2}{|c|}{2010} & \multicolumn{2}{|c|}{2017} \\
\hline & $r$ & $p$ & $r$ & $p$ & $r$ & $p$ & $r$ & $p$ \\
\hline Population density & -0.105 & 0.270 & -0.107 & 0.261 & -0.111 & 0.243 & -0.089 & 0.350 \\
\hline Per capita GDP & 0.135 & 0.155 & 0.217 & $0.021^{* *}$ & 0.323 & $0.001^{* *}$ & 0.334 & $0.000^{* * *}$ \\
\hline
\end{tabular}

\section{Discussion}

\subsection{Evolution of desertification sensitivity}

Based on analysis of the sensitivity change of desertification in northwest China over 18 years (2000-2017), this paper has analyzed the desertification evolution mechanism and the influential factors. Desertification formation is a process affected by multiple environmental factors. Soil, topography, climate, hydrology and vegetation are the most important factors in the arid region of northwest China. These factors influence each other and restrict each other, leading to different sensitivity degrees of desertification in different regions.

The complexity of the topography, the differences of the surface runoff and river distribution patterns are integrated to influence the different distribution characteristics for climate, vegetation coverage and soil matrix in the arid region of northwest China. It has formed the unique spatial distribution characteristics, that is low-sensitivity in peripheral and high internal. The evolution mechanism of the desertification sensitivity over the arid zone of northwest China is due to the long-term interaction of various environmental factors. But on a smaller regional scale, the effects of human production and life on the surrounding environment are the most rapid and direct factors that cause sensitivity changes in land desertification.

Because northwest China is deep in the Eurasian continent hinterland, there is little water vapor from the ocean and the plain precipitation is under $160 \mathrm{~mm}$, so there is basically no surface water runoff. These factors combine to form one of the harshest arid areas in the world, and under the background of the climate, slight weathering, material movement, water erosion and accumulation, and a wide range of wind erosion, transportation and accumulation, desert steppe has gradually formed. Most of the soil in this area is chestnut soil, ash calcium soil, sand soil and desert soil, the soil texture is loose and the particles are tiny. Under long-term wind erosion, the fine particles gradually converted into soil, sandy soil and gravel soil, and eventually forming desertification. In addition, vegetation is the most sensitive and basic factor affecting desertification. In the southeast of the Tarim Basin, Qaidam Basin and the west of Hexi Corridor, the vegetation coverage gradually decreases from inside of the basin to the periphery, which directly affects the spatial distribution pattern of desertification sensitivity, forming the spatial characteristics of low desertification sensitivity in the center of the basin and high sensitivity in the peripheral areas.

The intensity of human activities increases the load of the ecological environment bearing capacity in the arid region of northwest China. For example, excessive water retention or diversion, excessive exploitation of groundwater and other behaviors break the original 
weak balance of natural water resources. For the development of local socio-economy, uncontrolled reclamation of wasteland and mining of ore have seriously damaged the stability of the regional natural environment. Under the long-term influences, vegetation is bound to deteriorate, and land desertification will further expand. According to the current research results, the sensitivity of desertification in the arid northwest region is still at a high level. However, after the government implemented a series of ecological restoration projects, such as wind breaks and sand fixation, ecological afforestation, the trend of land desertification was step-down to a large extent, and the desertification overall environmental conditions was also improved. The results show that the highly sensitive land area decreased by about $4.78 \times 10^{4} \mathrm{~km}^{2}$ from 2000 to 2017 , and this change was particularly evident in oases and surrounding areas. Land desertification has had a profound impact on northwest China, and the mechanism of sensitivity change of desertification is the key to controlling and preventing land desertification.

\subsection{Suggestions for desertification control and land restoration}

As the victims of land desertification, humans also play the role of initiators to some extent. Therefore, under the background of increasing global climate change, human activities have become increasingly significant with social and economic development entering new normals; the environmental problems of land desertification in the arid region of northwest China are thus serious. Therefore, the prevention and control of future desertification and its sensitivity should be based on the following aspects.

(1) The core areas of the Altai Mountains, Tianshan Mountains, Kunlun Mountains, Altun Mountains and Qilian Mountains are the "ecological sources" of the arid northwest China. An ecological enclosure area should be set up, with the formulation of the policy on prohibition of grazing and logging, rest grazing and rotation grazing, establishment of a green barrier, and prevention of the expansion of desertification in these areas.

(2) Rational allocation of industrial structure, control of the exploitation of the mineral resources and the water-saving agriculture, forestry and animal husbandry structure should be developed for the future sustainable development. Ecological migration policy should be made in the densely-populated area and high desertification sensitivity area caused by unreasonable economic development. Ecological management projects and environmental governance policies should be adjusted and implemented simultaneously in order to promote the coordinated development of local ecology-society-economy.

(3) According to the evolution process of the formation of desertification, the original desert, the Gobi Desert, decertified land, etc., can be effectively distinguished. For native deserts and the Gobi Desert, the establishment of artificial windbreaks and sand fixation forests to stop desertification from spreading to surrounding areas is the focus of desertification control. For desertification land that is caused by human interference, it is necessary to strictly control the degradation and reduction of land, soil, vegetation and surface runoff caused by human behaviors such as land abuse, overgrazing and over irrigation. Ecological restoration projects should be carried out, with a focus on maintaining the existing vegetation, cultivating new types of wind-resistant and sand-fixing vegetation, improving the ecological conditions of sandy eroded poor land, and paying attention to the natural succession 
law of sandy plant communities, so as to ease the expansion pressure of regional land desertification.

\section{Conclusions}

Based on multi-source data from 2000 to 2017, a soil-topography-hydrology-climatevegetation evaluation index system of comprehensive sensitivity has been proposed, and an SDM was used to evaluate the desertification sensitivity pattern and spatiotemporal changes in northwest China. The main conclusions are as follows.

(1) Different influential factors are interrelated and mutually restricted, which together constitute the background conditions for the distribution and change of desertification sensitivity in northwest China. Vegetation cover and surface water reserves have displayed an increasing trend, and have prevented sensitivities from rising in recent years.

(2) The desertification sensitivity generally displays a low distribution characteristic on the periphery of the area and a high one in the interior. The low-sensitivity regions are mainly in the five major mountain ranges (Altai Mountains, Tianshan Mountains, Kunlun Mountains, Altun Mountains and Qilian Mountains), while the high-sensitivity regions are mainly distributed in regions such as the Junggar Basin, the Tarim Basin and the Inner Mongolia Plateau, as well as the Taklimakan Desert, Badain Jaran Desert and Tengger Desert. The spatial distribution of desertification sensitivity is obviously regional, and the highand low-sensitivity regions have distinctive boundaries with a concentrated distribution.

(3) Through analysis of the different sensitivity type conversions and mutual conversion conditions, it was found that most areas remained stable over the time period studied. The area transfer-in was greater than that of transfer-out, except for the extreme sensitivity type. The conversion characteristics were mainly continual increasing type and fluctuant increase type, which were more than the continual decreasing type and fluctuant decrease type. This indicated that the desertification sensitivity showed a decreasing trend, and did not display a sharp increase in desertification sensitivity. The potential desertification sensitivity decreased after 2010, which reflects that regional desertification control has gained remarkable achievements.

(4) The effects of different factors on the sensitivity of desertification have been compared. It was found that the internal driving factors such as soil, climate, vegetation and elevation had an interconnected effect on desertification sensitivity. Soil and climate played a direct role, and they were the most important influential factors. Vegetation cover was the most active and fundamental factor in desertification sensitivity change. In addition, the distribution of topography and the variation of hydrology restricted the sensitivity of desertification.

However, the sensitivity of desertification is still at a high level in northwest China, and the management of desertified land still has a long way to go. To avoid increased sensitivity, the area needs to remain alert and take measures to control desertification. In addition, the present governance measures should continue to keep and improve the decreased sensitivity areas.

This research provides a reference and decision-making basis for desertification prevention and control in the arid region of northwest China. In addition, the soil-topography- hy- 
drology-climate-vegetation comprehensive evaluation system for sensitivity and the SDM proposed in this study can solve some problems, such as the lack of emphasis on evaluation and sensitivity partition while ignoring dynamic changes and driving force analysis in the previous sensitivity evaluation. However, due to limited data and technical problems, this study did not combine the change mechanisms of desertification sensitivity. In addition, some factors such as government policy were not combined to evaluate sensitivity. Therefore, more attention should be paid to this area in the future research to provide change mechanisms for sustainable development.

\section{References}

Amani M, Salehi B, Mahdavi S et al., 2017. Temperature-Vegetation-soil Moisture Dryness Index (TVMDI). Remote Sensing of Environment, 197: 1-14.

Ahmed A, Nawaz R, Woulds C et al., 2020. Influence of hydro-climatic factors on future coastal land susceptibility to erosion in Bangladesh: A geospatial modelling approach. Journal of Geovisualization and Spatial Analysis, 4(1): 1-24.

Bi J X, Zhen J, Wang Y J et al., 2017. The method of enhanced Gaussian function weighted KNN indoor positioning. Bulletin of Surveying and Mapping, 6: 9-12.

Cristina N M, Valeria A M, 2017. Assessing the progress of desertification of the southern edge of Chihuahua Desert: A case study of San Luis Potosi Plateau. Journal of Geographical Sciences, 27(4): 420-438.

Cui B L, Li X Y, Jiang G H et al., 2011. Study on land use/cover in mountain area based on the DEM: Taking the Qinghai Lake Basin as an example. Journal of Natural Resources, 26(5): 871-880. (in Chinese)

Duan H C, Xue X, 2018. Spatio-temporal distribution of aeolian desertification in Horqin Sandy Land based on DEM. Journal of Arid Land Resources and Environment, 32(8): 74-79. (in Chinese)

Karamesouti M, Panagos P, Kosmas C, 2018. Model-based spatio-temporal analysis of land desertification risk in Greece. Catena, 167: 266-275.

Li D J, Xu D Y, Wang Z Y et al., 2018. Ecological compensation for desertification control: A review. Journal of Geographical Sciences, 28(3): 367-384.

Liu L Y, Li X Y, Shi P et al., 2007. Wind erodibility of major soils in the farming-pastoral ecotone of China. Journal of Arid Environments, 68(4): 611-623.

Ma Y, Tong Y, Ren J et al., 2018. Spatial-temporal pattern and driving factors of public participation in environmental regulation: Taking the Yangtze River Economic Belt as an example. Chinese Geographical Science, 38 (11): 1799-1808.

Mesquita D P, Gomes J P, Júnior A H et al., 2017. Euclidean distance estimation in incomplete datasets. Neurocomputing, 248: 11-18.

Salvati L, Bajocco S, 2015. Validation of MEDALUS fire risk index using forest fires statistics through a multivariate approach. Ecological Indicators, 48: 365-369.

Seyed M H, Sahar S, Mehdi F, 2012. Desertification hazard zoning in Sistan Region, Iran. Journal of Geographical Sciences, 22(5): 885-894.

Shi S, Wei W, Yang D et al., 2018. Spatial and temporal evolution of eco-environmental quality in the oasis of Shiyang River Basin based on RSEDI. Chinese Journal of Ecology, 37(4): 1152-1163. (in Chinese)

Sterk G, Boardman J, Verdoodt A, 2016. Desertification: History, causes and options for its control. Land Degradation \& Development, 27(8): 1783-1787.

Sun B F, Wang X K, 2015. On assessment of sandy desertification sensitivity in Xinjiang. Journal of Southwest China Normal University (Natural Science Edition), 40(7): 108-112. (in Chinese)

Symeonakis E, Karathanasis N, Koukoulas S et al., 2016. Monitoring sensitivity to land degradation and desertification with the environmentally sensitive area index: The case of Lesvos Island. Land Degradation and Development, 27(6): 1562-1573. 
Tian L, Qiu S J, Peng J et al., 2018. Desertification sensitivity evaluation in Inner Mongolia Autonomous Region based on PSR framework. Progress in Geography, 37(12): 1682-1692. (in Chinese)

United Nations, 1994. United Nations Convention to Combat Desertification in Those Countries Experiencing Serious Drought and/or Desertification, Particularly in Africa. Combat Desertification Office of Ministry of Forestry in the People's Republic of China, Trans. Beijing: China Forestry Publishing House. (in Chinese)

Wang G X, Li M, 2019. The spatial interaction between inter-provincial migration and manufacturing industry transfer. Chinese Geographical Science, 39(2): 183-194.

Wang J F, Xu C D, 2017. Geodetector: Principle and prospective. Acta Geographica Sinica, 72(1): 116-134. (in Chinese)

Wang Y, Zhou L H, Wei X, 2018. An evaluation index system of vulnerability of the desertification reversion process based on the socio-ecological systems theory. Acta Ecologica Sinica, 38(3): 829-840. (in Chinese)

Wang Y H, Zhang L B, Guo Y et al., 2014. Analysis of spatiotemporal pattern and tendency of land desertification sensitivity in six provinces of China. Research of Soil and Water Conservation, 21(5): 132-137.

Wei X X, Zhao J, Wei W et al., 2014. Coordinated development of ecological-economic system and spatial evolution based on county unit in China. Progress in Geography, 33(11): 1535-1545. (in Chinese)

Wei W, 2018. Land use optimal allocation based on CLUE-S and MCR model in Shiyang River Basin [D]. Lanzhou: Lanzhou University. (in Chinese)

Wei W, Guo Z C, Xie B B et al., 2019. Spatiotemporal evolution of environment based on integrated remote sensing indexes in arid inland river basin in Northwest China. Environmental Science and Pollution Research, 26: 13062-13084.

Wei W, Shi S, Zhang X Y et al., 2020. Regional-scale assessment of environmental vulnerability in an arid inland basin. Ecological Indicators, 109: 105792.

Xu D, You X, Xia C, 2019. Assessing the spatial-temporal pattern and evolution of areas sensitive to land desertification in North China. Ecological Indicators, 97: 150-158.

Xu D Y, Li C L, Zhuang D F et al., 2011. Assessment of the relative role of climate change and human activities in desertification: A review. Journal of Geographical Sciences, 21(5): 926-936.

Yang S Q, 2017. A case study of a novel sustainable agricultural development evaluation method based on Euclidean distance theory. Acta Ecologica Sinica, 37(11): 3840-3848. (in Chinese)

Zhai R J, 2011. Research on automated matching methods for multi-scale vector spatial data based on global consistency evaluation [D]. Zhengzhou: Information Engineering University. (in Chinese)

Zhang X S, 1994. Principles and optimal models for development of Maowusu sandy grassland. Acta Phytoecologica Sinica, 18(1): 1-16.

Zhao M Y, Zhao W W, Jin T et al., 2012. Land desertification sensitivity evaluation in Qinghai Lake Basin. Chinese Agricultural Science Bulletin, 28(32): 237-242. (in Chinese)

Zhao X F, Li Y Y, Zhao Y T et al., 2018. Spatiotemporal differences and driving factors of land development degree in China based on Geographical Detector. Resources and Environment in the Yangtze Basin, 27(11): 2425-2433. (in Chinese)

Zhou D, Shen Y J, Chen Y N et al., 2015. Estimation of ecological water requirement of desert vegetation in the arid region of Northwest China. Chinese Journal of Ecology, 34(3): 670-680. (in Chinese)

Zhou K, Fan J, Wang Y F et al., 2019. Evaluation of water resources carrying capacity and its guidelines for spatial planning in arid and semi-arid region: A case in Xiji-Haiyuan-Guyuan area of Ningxia. Chinese Geographical Science, 39(2): 232-241.

Zhou L, Dang X, Sun Q et al., 2020. Multi-scenario simulation of urban land change in Shanghai by random forest and CA-Markov model. Sustainable Cities and Society, 55: 1-10.

Zhou L, Zhou C, Che L et al., 2020. Spatio-temporal evolution and influencing factors of urban green development efficiency in China. Journal of Geographical Sciences, 30(5): 724-742.

Zhu D Y, Xiong K N, Xiao H et al., 2016. Comparison of rocky desertification detection ability of GF-1 and Landsat-OLI based on vegetation index. Journal of Natural Resources, 31(11): 1949-1957. (in Chinese)

Zhu Z D, 1991. Fragile ecological zones and land desertification in China. Journal of Desert Research, 11(4): 11-22. (in Chinese) 